\title{
В.Д. ЧЕРНЫЙ
}

\section{ИТАЛЬЯНСКАЯ ТЕМА В ДРЕВНЕРУССКОМ САДОВОМ ИСКУССТВЕ}

\author{
Валентин Дмитриевич Черный \\ Московский педагогический государственный университет, \\ Институт искусств, \\ кафедра истории художественной культуры, \\ профессор \\ Малая Пироговская ул., д. 1, стр. 6, \\ Москва, 119991, Россия \\ доктор культурологии \\ E-mail: tchernie@rambler.ru
}

Реферат. Рассматривается итальянское влияние на русское садовое искусство со второй половины XV до кониа XVII века. Высказывается версия о создании первых «итальянских» садов в период возведения архитектурного ансамбля Московского Кремля и реконструкиии окружающей его территории. Появление первых в Москве «верховых» садов связывается со строительством двориового комплекса великого князя. Их устройство было предусмотрено на сводах первого этажа зданий. Разбивка обширного сада за Москвой-рекой, напротив дворияа, была частью итальянского плана благоустройства территории вокруг Кремля и исходила из ренессансных приниипов его построения - вынести сад из замкнутого пространства на открытое, хорошо обозреваемое место. По свидетельству исторических источников, несмотря на ослабление контактов с Италией, «итальянский» облик кремлевского дворияа бережно сохранялся до XVII в., когда верховые сады получили более широкое распространение. В XVII столетии в России возникает интерес к загородным декоративным садам. Вид и планировка некоторых из садов подмосковной ияарской усадьбы Измайлово вызывали у иностранных путешественников прямые аналогии с итальянскими садами. К таковым можно отнести круглый «Аптекарский огород» $u$ «Сад с потешными палатами и лабиринтом». Некоторые литературные описания и гравюры подтверждают эти оценки. Многочисленные образцы западноевропейского садового искусства в период позднего Сред- невековья находились в одном из районов Москвь, Немеикой слободе, где постоянно проживали и итальянцы. Анализируются конкретные примеры освоения основ искусства итальянского Возрождения при создании древнерусских садов.

Ключевые слова: ландшафтная архитектура, сад, планировка, влияние, Ренессанс, дворец, усадьба.

Для цитирования: Черный В.Д. Итальянская тема в древнерусском садовом искусстве // Обсерватория культуры. 2017. Т. 14, № 1. С. 121-127.

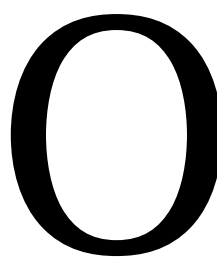

вкладе итальянцев в развитие русского зодчества конца XV - начала XVI в. писали многие исследователи [1-4]. Речь в их работах шла о строительстве крепостей, храмов, жилых комплексов, работе декораторов. Однако ландшафтная архитектура, в том числе садовое искусство, специалистами еще не рассматривалась. В лучшем случае они ограничивались общими фразами или высказывали отдельные версии. Между тем в летописях, записках иностранцев и русских путешественников, гравюрах и средневековых картах содержится немало свидетельств, подкрепленных натурными обследованиями памятников и археологическими изысканиями, говорящих о влиянии итальянских зодчих на русское декоративное садоводство.

Цель статьи заключается в оценке степени влияния итальянской культуры на развитие представлений русских людей о садовом искусстве и воплощение отдельных заимствований в памятниках русской ландшафтной архитектуры.

Одно из первых известных свидетельств русских источников об итальянских садах принадлежит неизвестному суздальцу из свиты московского митрополита Исидора, присутствовавшему на Флорентийском церковном соборе. Во время своего путешествия, продолжавшегося с 1437 по 1440 г., автор путевых заметок среди прочего отметил «садов... множество масличных», описал старые кедры и кипарисы [5, с. 139]. 
Устойчивые контакты русских с итальянской культурой начинаются с 1470-х гг. в процессе реализации глобальной задачи московских властей, направленной на восстановление русской государственности и повышение политического статуса. Это и стало причиной заключения великим князем Иваном III «политического брака» с Софией Палеолог, племянницей последнего византийского императора, пребывавшей все свои сознательные годы в папском дворце в Ватикане, и грандиозной перестройки ансамбля Московского Кремля. Не исключено, что связи и предпочтения византийской принцессы и определили выбор итальянских мастеров для осуществления замысла по возведению государственной резиденции. Перестройка ансамбля Московского Кремля, начавшаяся в 1470-е гг. итальянскими архитекторами, сделала актуальным вопрос об обустройстве как кремлевской, так и примыкающей к ней территорий. Особую актуальность этот аспект приобрел во время строительства великокняжеского дворцового комплекса. Его строительство осуществлялось разными итальянскими зодчими поэтапно, но, надо полагать, в соответствии с практикой итальянской архитектуры, по определенному плану и проектной документации.

Начало было положено возведением в $1487-$ 1491 гг. Большой (Грановитой) палаты, предназначенной для торжественных приемов, М. Фрязином и П.А. Солари, а завершилось в 1499-1508 гг. усилиями Алевиза Старого (Алои́зио да Кареза́но). Вероятно, на начальной стадии «общая схема дворцового комплекса» была создана А. Фьораванти [6, c. 130], а решающий вклад в разработку проекта на определенном этапе как организатор всех строительных работ внес П.А. Солари, обладавший самым высоким статусом среди итальянских зодчих, - главного архитектора Москвы («architectus generalis Moscovial») [3, c. 88].

Возведение нового дворца началось на обширной территории еще до завершения строительства Грановитой палаты в 1491 году. Во всяком случае, в послании архиепископа новгородского Геннадия митрополиту Зосиме, написанном в 1490 г., владыка порицает великого князя за «вынос из города вон» старых монастырей, церквей и кладбищ [7, с. 88]. «Да на тех местах, - по словам Геннадия, - сад посажен». В назидание он приводит фразу из Второзакония Моисея: «Да не насади себе садов, ни древа, подле требника Господа Бога своего». Геннадий даже высказал предложение, как сохранить вынесенные из Кремля храмы: «А что, которые церкви были в городе, а то также бы подняти на подклетех, да сени нарядити вокруг церкви; и коли случится выйти великому князю или великой княгине саду посмотрети, и он бы поседел у церкви: ано лепо видети» [8, с. 373-379]. Должно быть, упоми- нание в тексте послания великой княгини не случайно. Австрийский дипломат С. Герберштейн, в 1517 и 1526 гг. посетивший Москву, пишет о Софии Палеолог как о «небыкновенно хитрой женщине», оказывающей большое влияние на Ивана III («по ее научению великий князь сделал многое») [9, с. 66]. Исследователи убеждены, «что и общие планы, и детали перестройки Кремля обдумывались и обсуждались в весьма узком кругу и, наверное, при активном участии Софьи Палеолог и главных итальянских мастеров» [10, с. 29].

С.С. Подъяпольский, анализировавший деятельность итальянских зодчих в Москве, убежден, что княжеский дворец изначально ориентировался на итальянский образец. В подтверждение этого мнения автор приводит слова Алевиза Старого, согласно которым Иван III хотел, чтобы его замок был «наподобие того, что в Милане». У иностранцев, посетивших Россию в XVI столетии, облик дворца вызывал прямые ассоциации с итальянскими постройками [2, с. 33-34]. На Руси вскоре после завершения работ также отметили необычность конструкций, оформления зданий и их композиции. В частности, в Степенной книге середины XVI в. составитель обратил внимание на непривычный для русского человека вид дворца: «весь прехитро камен же поставлен бысть» [11, с. 554.]. Как отмечал С.С. Подъяпольский, «термин “прехитро” должен указывать на элемент необычности, но он может быть отнесен как к композиции и конструкции здания, так и к его декорации, что не менее вероятно» [2, с. 81].

Сколько и каких садов было «насажено» у дворца при итальянцах источники не уточняют. Один из садов был разбит между дворцовыми корпусами и Конюшенным двором, где сейчас стоит Оружейная палата. Там уже в XX в. нашли корни и пни фруктовых деревьев [12, с. 157]. Не исключено, что речь могла идти, в том числе, о верховом саде, устроенном на кровле-террасе (т. е. на сенях). Намек на это содержится и в послании архиепископа Геннадия: если князю и княгине случится выйти на сени «саду посмотрети», можно было бы посидеть у церкви и полюбоваться красотой. В.Л. Глазычев высказал версию, что таким садом, устроенным еще в конце XV в., был «Верхний Набережный» [6, с. 130]. Хотя об устройстве Верхнего и Нижнего верховых садов сообщается только в 1680-х гг., существуют свидетельства об их более раннем происхождении. По свидетельству источников начала XVII в., за садами, находящимися где-то «в верху», садовники ухаживали и в 1620 -е и 1630 -е гг., а государственная казна на эти цели исправно выделяла средства, что фиксировалось в приходно-расходных книгах [13, с. 110]. Таким образом, предположение о появлении первых верховых садов еще на рубеже XV-XVI вв. 
представляется вероятным. Идея устройства камерного «закрытого сада» связывается В.Л. Глазычевым с личностью Софии Палеолог, которая «должна была стремиться собственные покои учредить по образцу знакомых ей итальянских» [6, с. $130-131]$.

Одновременно со строительными работами в самом Кремле начинается обустройство прилегавшей к нему территории. В 1493 г. после очередного пожара земля вокруг цитадели освобождается от всей деревянной застройки на 109 саженей (около 238 м) [14, с. 183]. Важно понять, насколько это решение Ивана III было связано с проектом итальянских архитекторов по реконструкции кремлевских окрестностей. Косвенно об их причастности к данному решению говорит то, что освобожденная поверхность земли в некоторых местах была вымощена ровным слоем камня [15, с. 211-230]. Устроить каменный настил, очевидно, предложили итальянцы, так как на Руси традиционно использовались деревянные мостовые.

Как очередной этап переустройства прилегающей к кремлевскому ансамблю территории, вслед за работами 1493 г., стоит рассматривать и распоряжение великого князя в 1495 г. напротив Кремля, за рекой, «чинити» обширный Государев сад [16, с. 240]. Сад этот должен был особенно хорошо обозреваться с высоты Боровицкого холма, из Набережных палат, предназначенных для переговоров с иностранными послами [17, с. 109]. Вынос сада из замкнутого пространства огороженного двора «на окружающие просторы - характерный признак ренессансного мышления. Такой подход принципиально отличался от средневекового принципа оградить личное пространство» [18, c. 173]. Этот проект в полной мере согласуется с логикой культуры эпохи Возрождения. Созданный на противоположном берегу сад становился иллюзорной частью дворца. Так воплощался один из ренессансных принципов построения сада, который словно вырывался из «застенков» Средневековья на открытое место [19, с. 169-199].

О том, что это был не обычный сад хозяйственного назначения, по неизвестным причинам приближенный к княжеской резиденции, говорят многочисленные изобразительные источники. Самые древние из дошедших до нас изображений Государева сада, миниатюры Лицевого летописного свода XVI в., созданного в 1570-е гг., воспроизводят его образ крайне схематично. Гораздо больше информации об особенностях его планировки дают планы Москвы конца XVI - первой половины XVII в.: «Петров чертеж» (1507-1599), «Годунов чертеж» (начало 1600-х гг.), «Сигизмундов план» (1610), «План М. Мериана (1643) и «План Олеария» (1656). На всех чертежах, несмотря на их схематичность и вариативность, сад имеет декора- тивные очертания в форме вытянутого вдоль реки неправильного прямоугольника, равного длине набережной стороны кремлевской стены с территорией, разбитой на квадратные куртины. Их внутренняя планировка имеет геометрический, подчас причудливый рисунок. Наиболее подробно этот замоскворецкий сад запечатлен на плане А. Олеария. На чертеже, наряду со строгими рядами деревьев и шестью вытянутыми прямоугольными участками, показаны две одинаковые, но более сложные по планировке куртины. Их пересекают аллеи, а в центре разбиты маленькие круглые клумбы, окруженные дорожкой. Планы подобной конфигурации часто встречаются на изображениях итальянских садов, например, на фреске 1574-1578 гг. виллы Ланте. Разумеется, со временем сад в Замоскворечье терял черты своей первозданности, сохраняя только отдельные исконные элементы.

Надо полагать, создание обширного Государева сада и других насаждений в Кремле оживило интерес к садоводству и у широких слоев москвичей. Во всяком случае, в записках начала XVI в. итальянского литератора П. Йовия, со слов русского посланника Дмитрия Герасимова, сообщается, что в Москве «почти все дома имеют сады, как для разведения овощей, так и для удовольствия» [20, с. 271]. Это свидетельство посла подтвердил шведский дипломат П. де Ерлезунда, хорошо знавший Москву. Он прослужил четыре года при дворе Бориса Годунова, а затем дважды в течение десятилетия побывал в русской столице. По словам шведского посланника, «в городе много деревьев и увеселительных садов, занимающих довольно места» [21, с. 161].

Многочисленные итальянские мастера, работавшие в России с конца XV до 40-х гг. XVI в., пребывавшие здесь на правах обласканных пленников, внесли заметный вклад в развитие культуры Московии. Итальянцы, получая за свой квалифицированный труд щедрые великокняжеские дары разного рода - поместья, одежду и прочее, были ограничены в свободе и не могли свободно покинуть Россию [3, с. 73]. С начала XVI в. наблюдается резкое сокращение числа русских посольств в Италию, а с 1528 г. контакты двух стран прерываются на несколько десятилетий. Охлаждение отношений с прежним партнером, по наблюдениям Я.С. Лурье, сказывается и на стиле русских произведений - из них «почти совсем исчезают» элементы Возрождения [22, с. 199]. На смену масштабному строительству приходит «активное осмысление и переработка того нового, что внесли в русское зодчество итальянские архитекторы» [3, с. 84]. Вместе с тем созданный итальянцами кремлевский дворцовый ансамбль бережно сохранялся и в последующее столетие. По свидетельству персидского дипломата Орудж- 
бек Баяйта, посетившего Москву на рубеже XVIXVII вв., царский дворец был по-прежнему «спланирован на итальянский манер» [23, с. 45].

О состоянии садов, созданных при итальянцах и, вероятно, при их непосредственном участии, во второй половине XVI в. почти ничего неизвестно. Судя по всему, состояние некоторых из них бережно поддерживалось, поскольку источники начала XVII в. о них по-прежнему упоминают. По образцу сохранившихся кремлевских верховых садов в 1635 г. царские садовники И. Телятевский и Т. Андреев «строят» сады «на дворце, вверху и на Борисовом дворе», где уже стояло «государево место». Возможно, первый из названных садов находился на подклетах между церквями Святой Екатерины и Спаса Нерукотворного и изначально предназначался для царевича Алексея Михайловича. Второй сад был устроен «на взрубе», на дворе Бориса Годунова, возведенном на рубеже XVI-XVII веков $[13$, c. 110]. Садовники могли посадить растения, но они были не в силах возвести для них архитектурную основу - это могли выполнить ранее итальянские строители.

Об обновлении своих садов постоянно заботились и цари. В 1657 г. царь Алексей Михайлович требует срочно посадить в своем «верхнем» саду цветы, так же как в Аптекарском огороде [24, c. 13-14]. Примечательно, что созданные на рубеже 1670-1680-х гг. верховые Набережные сады представляли собой тип «замкнутых» средневековых. Возможно, они возводились с оглядкой на те «очаги отдохновения», которые в свое время устраивали в княжеском дворце итальянские мастера.

Новый всплеск интереса к итальянской архитектуре и садам в частности проявился во второй половине XVII в. и поддерживался властными структурами. В заметках, оставленных не только русскими путешественниками, но и официальными посланниками, посещавшими Италию, содержится немало описаний садов. В круг внимания попадали особенности планировки, виды растений, садовые постройки и иные «внешние» признаки ландшафтной архитектуры. В статейные списки посольств (отчеты о поездках) включались и личные впечатления. Так, стольник В.Б. Лихачев, посетивший Флоренцию в 1658-1659 гг., пишет об удивившей его «красоте в садах». Он выделяет увиденные кедровые и кипарисовые деревья, «яблоки предивные», «виноград двойной» (т. е. белого и вишневого цвета) и другие диковины. Более разнообразно описал садовопарковое искусство итальянских городов стольник П.А. Толстой, обучавшийся в Венеции морскому делу. В его записках 1690-х гг. описывается планировка, ландшафт, своеобразие таких сооружений, как гроты, павильоны, лабиринты. Стольника заинтересовали фонтаны, которые, по его словам, «зделаны преудивительным мастерством», и скульп- туры («а поставлены те все подобия промеж цветов для украшения того саду») [25, с. 104-119].

Многие элементы европейского и, в частности, итальянского садоводства со второй половины XVII в. начинают воплощать в русских, прежде всего царских, загородных садах. Больше всего на этот счет известно о подмосковной царской усадьбе в селе Измайлово, сочетавшей качества передового опытного хозяйства и современного садово-паркового комплекса. Здесь, на территории, простиравшейся на многие версты, было устроено не менее пяти разнообразных регулярных садов. Дошедшие до нас чертежи и описи позволяют утверждать, что некоторые них явно восходили к традициям Возрождения. По словам польского посла Б. Таннера, эта местность «полюбилась царю, и он для своего удовольствия устроил и развел в ней два сада, из коих один убран на подобие итальянских...» [26, с. 70]. Поскольку описание этого сада в сочинении отсутствует, можно только догадываться, какой именно объект имеется в виду. Скорее всего, речь идет об «Аптекарском огороде», известном по чертежу 1670 года. Этот сад, представлявший собой круг диаметром 280 м, имел радиально кольцевую планировку. По периметру он делился на три концентрические аллеи, сужающиеся к центру. Радиальные аллеи делили круг на десять секторов. Подобный сад на острове Цереры был описан в романе Ф. Колонны «Гинторомахия Полифила», написанном в середине XV века. Он имел круглую форму, за оградой, границу которой выполняли высаженные кипарисы. «концентрически в глубину идут еще десять делений по окружности - ограда из миртов, апельсиновых и лимонных деревьев... а от центра к периферии на равном расстоянии друг от друга расходятся двадцать радиальных линий, как бы проецируя на пространство сада систему сегментов и трапециевидных фигур, оптически воспринимаемых как треугольники и прямоугольники» $[27$, с. $162-163]$. Судя по изобразительным источникам, сады, имеющие такие планы, воплощающие идею «абсолютно правильной композиции», были распространены в Италии. Их можно увидеть, например, на гравюрах XVI в. с изображениями садов Падуи, Боболи во Флоренции и др.

Еще один измайловский сад, который может восходить к итальянским образцам, - «Потешный сад с лабиринтом». Его аннотированный план (ок. 1670 г.) представляет сложный по составу комплекс, окруженный рвом с водой, из двух ворот (одни из них с лестничными всходами), четырех павильонов разного назначения и четырех крестообразно расположенных садовых участков (куртин) с барочной разбивкой. В средокрестии композиции находился большой квадратный лабиринт, выстроенный кустарником и низкорослой вишней, а в самом цен- 
тре - фонтан («ключь, ис сего вода бежит»). Заявленная в проекте театральность, нарядные павильоны, обилие водных элементов - преград и фонтана, куртины с затейливым рисунком допускают, что к созданию плана мог быть причастен итальянский архитектор. Косвенно на европейское происхождение планов «Аптекарского огорода» и «Потешного сада» указывают номера объектов, проставленные арабскими цифрами, в то время как на Руси еще пользовались буквенными знаками $[28$, с. 88].

Разумеется, так называемые «итальянские сады» распространялись не только в царских владениях. Они встречались и в усадьбах знатных горожан западноевропейского происхождения. Таким местом, например, была Немецкая слобода, где проживали выходцы из разных стран, в том числе Италии. «Едва ли найдешь здесь дом без сада, притом сады цветущие, плодоносные и красивые», писал об иностранной слободе в 1669 г. И. Давид [29, с. 124]. Эту характеристику подтвердил Б. Таннер буквально через несколько лет: «При каждом доме есть хорошо содержимый сад, засаженный латуком и цветами...» [26, с. 69]. Лучшие из садов Немецкой слободы были примером для состоятельных москвичей, готовых к преобразованиям.

В целом влияние итальянцев на русское садовое искусство, при всей его очевидности, нельзя считать устойчивым. Особенно сильно оно проявилось на рубеже XV-XVI вв. в период восстановления русской государственности после столетий раздробленности. В это время в Москве были востребованы высокие образцы архитектуры и лучшие в Европе зодчие для утверждения на международной арене. Однако географическая и религиозная удаленность Италии от России препятствовали развитию постоянных культурных отношений с ней, в том числе в области ландшафтной архитектуры. Эти контакты в XVI-XVII вв. носили спонтанный характер и определялись личным выбором отдельных состоятельных представителей русского общества.

\section{Список источников}

1. Лазарев В.Н. Искусство средневековой Руси и Запад (XI-XV века) // Византийское и древнерусское искусство. Москва : Наука, 1978. С. 227-296.

2. Подъяпольский С.С. Архитекторы итальянского Возрождения в России // Архитектурное наследство. Москва, 2003. Вып. 45. С. 30-41.

3. Подъяпольский С.С. Деятельность итальянских мастеров на Руси и в других странах Европы в конце XVначале XVI века // Советское искусствознание. Москва : Сов. художник, 1986. № 20. С. 62-93.

4. Подъяпольский С.С. Московский Кремлевский дворец в XVI в. по данным письменных источников // Древнерусское искусство. Русское искусство позднего средневековья: XVI век. Санкт-Петербург : Дмитрий Буланин, 2003. С. 99-119.
5. Хождение на Флорентийский собор Неизвестного Суздальца // Книга хожений. Записки русских путешественников XI-XV вв. Москва : Советская Россия, 1984. C. $137-151$.

6. Земцов С.М., Глазычев В.Л. Аристотель Фьораванти. Москва : Стройиздат, 1985. 184 с.

7. Петров Д.А. Архитектурный комментарий к одному месту из Послания архиепископа Геннадия митрополиту Зосиме // Древняя Русь. 2015. № 2 (60), июнь. С. 84-93.

8. Казакова Н.А., Лурье Я.С. Антифеодальные еретические движения на Руси XIV - начала XVI в. Москва ; Ленинград : АН СССР, 1955. С. 373-379.

9. Герберштейн С. Записки о Московии. Москва : МГУ, $1988.430 \mathrm{c}$.

10. Архитектурные ансамбли Москвы XV - начала $\mathrm{XX}$ веков. Принципы художественного единства / под ред. Т.Ф. Саваренской. Москва : Стройиздат, 1997. $471 \mathrm{c.}$

11. Книга Степенная царского родословия // Полное собрание русских летописей. Санкт-Петербург, 1908. Т. 21. Ч. 2. $350 \mathrm{c}$.

12. Сытин П.В. История планировки и застройки Москвы. Москва, 1950. Т. 1. 416 с.

13. Забелин И.Е. Домашний быт русских царей в XVI и XVII столетиях. Москва : Книга 1990. Кн. 1. 312 c.

14. Московский летописный свод конца XV века / Полное собрание русских летописей. Москва ; Ленинград, 1949. 464 с.

15. Чернов С.З., Бойцов И.А. Раскопки в Историческом проезде и изучение Великого Посада Москвы XIIIXIV вв. // Советская археология. 1992. № 1. С. $211-$ 230.

16. Летописный сборник, именуемый Патриаршею или Никоновской летописью // Полное собрание русских летописей. Санкт-Петербург, 1901. Т. 12. 278 c.

17. Черный В.Д. Русские средневековые сады: опыт классификации. Москва : Рукописные памятники Древней Руси, 2010. 176 с.

18. Козлова С.И. Ренессансный сад Италии и его предшественники // Сад: символы, метафоры, аллегории. Москва : Памятники исторической мысли, 2010. С. $158-165$.

19. Соколов М.Н. Принцип рая: главы об иконологии сада, парка и прекрасного вида. Москва : ПрогрессТрадиция, 2011. 704 с.

20. Йовий П. Книга о московском посольстве к Иоанну Руфу, архиепископу Константинопольскому // Россия в первой половине XVI в.: взгляд из Европы. Москва : Русский мир, 1997. С. 217-301.

21. Петрей П. История о великом княжестве Московском // О начале войн и смут в Московии. Москва : Рита-Принт, 1997. С. 151-464.

22. Лурье Я.С. Элементы Возрождения на Руси в конце XV - первой половине XVI века // Литература эпо- 
хи Возрождения и проблемы всемирной литературы. Ленинград : Наука, 1967. С. 183- 211.

23. Орудж-бек Баяйт. Россия и Европа глазами Оруджбек Баяйта. Санкт-Петербург : СПб. университет, 2007. 212 c.

24. Забелин И.Е. Московские сады в XVI столетии // Журнал садоводства. 1856. № 1. С. 1-42.

25. Головин В.П. Италия в восприятии русских путешественников второй половины XVII века // Итальянский сборник. Москва : Наука, 1999. Вып. 1. С. $104-119$.
26. Таннер Б. Описание путешествия польского посольства в Москву в 1678 г. Москва, 1891. 203 с.

27. Козлова С.И. Ренессансная концепция итальянского сада (по литературным источникам) // Искусство и культура Италии эпохи Возрождения и Просвещения. Москва : Наука, 1997. С. 161-176.

28. Тии А.А. Загадки древнерусского чертежа. Москва : Стройиздат, 1978. 151

29. Давид И. Современное состояние великой России, или Московии // Вопросы истории. 1968. № 1. С. $123-$ 132.

\section{ITALIAN THEME IN THE OLD RUSSIAN GARDEN ART}

\author{
VALENTIN D. CHERNYI \\ Moscow State Pedagogical University, 1, Building 6, \\ Malaya Pirogovskaya St., Moscow, 119991, Russia \\ E-mail: tchernie@rambler.ru
}

\begin{abstract}
The article reviews the Italian influence on the Russian garden art from the second half of the 15th to the end of the 17th century. It considers the version that the first "Italian" gardens were created during the period of the Moscow Kremlin architectural ensemble building and the surrounding area reconstruction. The appearance of the Moscow first "upper" gardens is associated with the construction of the Grand Prince's Palace complex. The gardens were organized on the ground floor arches of the buildings. Planting of a vast garden across the Moscow River, opposite the Palace, was a part of the Italian development plan for the territory around the Kremlin and was based on the Renaissance principles of its construction - relocation of the garden from a confined space to an open, well-surveyed place. According to historical sources, despite the weakening of contacts with Italy, the "Italian" look of the Kremlin Palace had been carefully preserved up to the 17th century, when the upper gardens had become widespread. In the 17th century, there was growing interest in the countryside decorative gardens in Russia. The look and layout of some of the gardens around the suburban Tsar Estate Izmaylovo put foreign travelers in remembrance of Italian gardens. Those gardens were the "Apothecary Garden" and the "Garden with the Amusing Chambers and Maze". Some literary descriptions and engravings confirm these assessments. Numerous examples of the West European garden art of the late Middle Ages could be found in one of Moscow districts - the German Quarter - where there were Italians among the permanent residents as well. The article analyzes the specific examples of utilization of the Italian Renaissance art in the creation of the Old Russian gardens.
\end{abstract}

Key words: landscape architecture, garden, layout, influence, the Renaissance, palace, estate.

Citation: Chernyi V.D. Italian Theme in the Old Russian Garden Art, Observatory of Culture, 2017, vol. 14, no. 1, pp. 121-127.

\section{References}

1. Lazarev V.N. Iskusstvo srednevekovoi Rusi i Zapad (XIXV veka) [The Art of Medieval Russia and the West (11th-15th Century)], Vizantiiskoe i drevnerusskoe iskusstvo [Byzantine and Old Russian Art]. Moscow, Nauka Publ., 1978, pp. 227-296.

2. Podyapolsky S.S. Arkhitektory ital'yanskogo Vozrozhdeniya v Rossii [Architects of the Italian Renaissance in Russia], Arkhitekturnoe nasledstvo [Architectural Heritage]. Moscow, 2003, issue 45, pp. 30-41.

3. Podyapolsky S.S. Deyatel'nost' ital'yanskikh masterov na Rusi i v drugikh stranakh Evropy v kontse XV-nachale XVI veka [Practice of the Italian Masters in Russia and in Other European Countries in the Late 15th-Early 16th Century], Sovetskoe iskusstvoznanie [Soviet Art Studies]. Moscow, Sovetskii Khudozhnik Publ., 1986, no. 20, pp. 62-93.

4. Podyapolsky S.S. Moskovskii Kremlevskii dvorets v XVI v. po dannym pis'mennykh istochnikov [The Moscow Kremlin Palace in the 16th Century, According to Written Sources], Drevnerusskoe iskusstvo. Russkoe iskusstvo pozdnego srednevekov'ya: XVI vek [Old Russian Art. The Russian Art of the Late Middle Ages: the 16th Century]. St. Petersburg, Dmitry Bulanin Publ., 2003, pp. 99119.

5. Khozhdenie na Florentiiskii sobor Neizvestnogo Suzdal'tsa [Pilgrimage to the Council of Florence by an Unknown Suzdal Resident], Kniga khozhenii. Zapiski russkikh puteshestvennikov XI-XV vv. [The Pilgrimages Book. Notes of Russian Travelers of the 11th15th Centuries]. Moscow, Sovetskaya Rossiya Publ., 1984, pp. 137-151.

6. Zemtsov S.M., Glazychev V.L. Aristotele Fioravanti. Moscow, Stroiizdat Publ., 1985, 184 p. (in Russ.).

7. Petrov D.A. Arkhitekturnyi kommentarii k odnomu mestu iz Poslaniya arkhiepiskopa Gennadiya mitropolitu Zosime 
[Architectural Comment to One Passage from the Message of Archbishop Gennady to Metropolitan Zosima], Drevnyaya Rus' [Old Russia], 2015, no. 2 (60), June, pp. 84-93.

8. Kazakova N.A., Lurie Ya.S. Antifeodal'nye ereticheskie dvizheniya na Rusi XIV - nachala XVI v. [Anti-Feudal Heretical Movements in Russia of the 14th - Beginning of 16th Century]. Moscow, Leningrad, AN SSSR Publ., 1955, pp. 373-379.

9. Herberstein S. Zapiski o Moskovii [Notes on Muscovite Affairs]. Moscow, MGU Publ., 1988, 430 p.

10. Savarenskaya T.F. (ed.) Arkhitekturnye ansambli Moskvy $X V$ - nachala XX vekov. Printsipy khudozhestvennogo edinstva [Architectural Ensembles of Moscow of the 15th Early 20th Centuries. The Principles of Artistic Unity]. Moscow, Stroiizdat Publ., 1997, 471 p.

11. Kniga Stepennaya tsarskogo rodosloviya [The Book of Degrees of the Royal Genealogy], Polnoe sobranie russkikh letopisei [Complete Collection of Russian Chronicles]. St. Petersburg, 1908, vol. 21, part 2, 350 p.

12. Sytin P.V. Istoriya planirovki i zastroiki Moskvy [The History of Layout and Development of Moscow]. Moscow, 1950, vol. 1, $416 \mathrm{p}$.

13. Zabelin I.E. Domashnii byt russkikh tsarei $v$ XVI $i$ XVII stoletiyakh [Home Life of Russian Tsars in the 16th and 17th Centuries]. Moscow, Kniga Publ., 1990, book 1, $312 \mathrm{p}$.

14. Moskovskii letopisnyi svod kontsa XV veka [Moscow Chronicle of the End of the 15th Century], Polnoe sobranie russkikh letopisei [Complete Collection of Russian Chronicles]. Moscow, Leningrad, 1949, 464 p.

15. Chernov S.Z., Boitsov I.A. Raskopki v Istoricheskom proezde i izuchenie Velikogo Posada Moskvy XIII-XIV vv. [The Excavations in the Istorichesky Proezd and the Investigations of Veliky Posad in Moscow in the 13th 14th Centuries], Sovetskaya arkheologiya [Soviet Archaeology], 1992, no. 1, pp. 211-230.

16. Letopisnyi sbornik, imenuemyi Patriarsheyu ili Nikonovskoi letopis'yu [The Chronicle Collection, Called the Patriarch's or Nikon Chronicle], Polnoe sobranie russkikh letopisei [Complete Collection of Russian Chronicles]. St. Petersburg, 1901, vol. 12, 278 p.

17. Chernyi V.D. Russkie srednevekovye sady: opyt klassifikatsii [Russian Medieval Gardens: the Experience of Classification]. Moscow, Rukopisnye Pamyatniki Drevnei Rusi Publ., 2010, 176 p.

18. Kozlova S.I. Renessansnyi sad Italii i ego predshestvenniki [The Renaissance Gardens of Italy and its Predecessors], Sad: simvoly, metafory, allegorii [The Garden: Symbols, Metaphors, Allegories]. Moscow, Pamyatniki Istoricheskoi Mysli Publ., 2010, pp. 158-165.
19. Sokolov M.N. Printsip raya: glavy ob ikonologii sada, parka i prekrasnogo vida [Principle of Paradise: Chapters on the Iconology of Garden, Park and Beautiful View]. Moscow, Progress-Traditsiya Publ., 2011, 704 p.

20. Giovio P. Kniga o moskovskom posol'stve k Ioannu Rufu, arkhiepiskopu Konstantinopol'skomu [The Book of the Moscow Embassy to John Rufus, Archbishop of Constantinople], Rossiya v pervoi polovine XVI v.: vzglyad iz Evropy [Russia in the First Half of the 16th Century: the View from Europe]. Moscow, Russkii Mir, 1997, pp. 217-301.

21. Petreius P. Istoriya o velikom knyazhestve Moskovskom [The Story of the Grand Duchy of Moscow], O nachale voin $i$ smut $v$ Moskovii [On the Beginning of Wars and Unrest in Muscovy]. Moscow, Rita-Print Publ., 1997, pp. 151-464.

22. Lurie Ya.S. Elementy Vozrozhdeniya na Rusi v kontse $\mathrm{XV}$ - pervoi polovine XVI veka [Elements of the Renaissance in Russia in the Late 15th - First Half of the 16th Century], Literatura epokhi Vozrozhdeniya i problemy vsemirnoi literatury [Literature of the Renaissance and the Problems of World Literature]. Leningrad, Nauka Publ., 1967, pp. 183- 211.

23. Uruch Beg Bayat. Rossiya i Evropa glazami Orudzh-bek Bayaita [Russia and Europe through the Eyes of Uruch Beg Bayat]. St. Petersburg, SPb. Universitet Publ., 2007, 212 p.

24. Zabelin I.E. Moskovskie sady v XVI stoletii [Moscow Gardens in the 16th Century], Zhurnal sadovodstva [Journal of Gardening], 1856, no. 1, pp. 1-42.

25. Golovin V.P. Italiya v vospriyatii russkikh puteshestvennikov vtoroi poloviny XVII veka [Italy in the Perception of Russian Travelers of the Second Half of the 17th Century], Ital'yanskii sbornik [Italian Collection]. Moscow, Nauka Publ., 1999, issue 1, pp. 104-119.

26. Tanner B. Opisanie puteshestviya pol'skogo posol'stva $v$ Moskvu $v 1678 \mathrm{~g}$. [Description of the Journey of the Polish Embassy in Moscow in 1678]. Moscow, 1891, 203 p.

27. Kozlova S.I. Renessansnaya kontseptsiya ital'yanskogo sada (po literaturnym istochnikam) [The Renaissance Concept of the Italian Garden (from Literary Sources)], Iskusstvo $i$ kul'tura Italii epokhi Vozrozhdeniya i Prosveshcheniya [Art and Culture of Italy of the Renaissance and Enlightenment]. Moscow, Nauka Publ., 1997, pp. 161-176.

28. Tits A.A. Zagadki drevnerusskogo chertezha [Mysteries of the Old Russian Drawing]. Moscow, Stroiizdat Publ., 1978, $151 \mathrm{p}$.

29. David I. Sovremennoe sostoyanie velikoi Rossii, ili Moskovii [Current State of Great Russia or Muscovy], Voprosy istorii [Questions of History], 1968, no. 1, pp. 123-132. 